\title{
Model experiments related to outdoor propagation over an earth berm
}

\section{Rasmussen, Karsten Bo}

\section{Published in:}

Acoustical Society of America. Journal

Link to article, DOI:

10.1121/1.411404

Publication date:

1994

\section{Document Version}

Publisher's PDF, also known as Version of record

Link back to DTU Orbit

Citation (APA):

Rasmussen, K. B. (1994). Model experiments related to outdoor propagation over an earth berm. Acoustical Society of America. Journal, 96(6), 3617-3620. https://doi.org/10.1121/1.411404

\section{General rights}

Copyright and moral rights for the publications made accessible in the public portal are retained by the authors and/or other copyright owners and it is a condition of accessing publications that users recognise and abide by the legal requirements associated with these rights.

- Users may download and print one copy of any publication from the public portal for the purpose of private study or research.

- You may not further distribute the material or use it for any profit-making activity or commercial gain

- You may freely distribute the URL identifying the publication in the public portal

If you believe that this document breaches copyright please contact us providing details, and we will remove access to the work immediately and investigate your claim 


\title{
Model experiments related to outdoor propagation over an earth berm
}

\author{
Karsten Bo Rasmussen \\ The Acoustics Laboratory, Building 352, Technical University of Denmark, DK-2800 Lyngby, Denmark
}

(Received 11 August 1993; revised 6 June 1994; accepted 25 July 1994)

\begin{abstract}
A series of scale model experiments related to outdoor propagation over an earth berm is described. The measurements are performed with a triggered spark source. The results are compared with data from an existing calculation model based upon uniform diffraction theory. Comparisons are made in the frequency domain as well as in the time domain and good agreement is obtained.
\end{abstract}

PACS numbers: 43.28.Fp, 43.50.Vt

\section{INTRODUCTION}

Scale model acoustic experiments can introduce a number of errors in comparison with full-scale measurements, since not all physical phenomena involved are transformed according to a linear scaling factor. The influence of atmospheric absorption as well as boundary layer effects are two such examples of phenomena which are not transformed according to scale.

Nevertheless, scale modeling has a number of significant advantages too. The physical parameters are very well controlled and the atmosphere is homogeneous and still. In this work, a series of measurements involving an artificial earth berm on a canvas surface simulating grass covered ground is reported. The results are compared with existing theory in the frequency domain as well as in the time domain.

\section{SCALE MODEL MEASUREMENTS}

A newly developed scale model facility ${ }^{1}$ has been used for the measurements. The facility is based upon a triggered spark source using a spark energy of $0.25 \mathrm{~J}$ or less. An energy level of $0.25 \mathrm{~J}$ was found to be sufficiently low to avoid nonlinear effects so long as the spark source was $5 \mathrm{~cm}$ from the surface. The source is constructed with 40-mm-long electrodes in order to reduce unwanted reflection and has a spark gap of $0.5-1 \mathrm{~mm}$. The source is controlled by a PC resident board using two ADSP2101 processors. The board is also used for event recording of the received signal. The receiver chain consists of a B\&K $4138 \frac{1}{8}$-in. microphone and a battery powered B\&K 2804 power supply followed by a battery powered low-noise amplifier and antialiasing filter. The setup is used with a scaling factor of 1:25. This scale factor was the largest possible with the setup used. The results shown in this work are obtained by time-domain averaging over 16 impulse responses using a sampling frequency of $600 \mathrm{kHz}$. The averaged impulse responses obtained are then edited and Fourier transformed (FFT with 1024 data points).

The grass-covered ground was modeled by a canvaslayer on top of a hard surface. This has previously been found ${ }^{1}$ to represent a flow resistivity of $500 \mathrm{kN} \mathrm{s} \mathrm{m}^{-4}$ in the well-established Delany-Bazley formulas. The earth berm model was made of plywood and was assumed to have an infinite impedance. Figure 1 displays the basic geometry. The internal angle of the wedge representing the earth berm is $90^{\circ}$ and the wedge is $240 \mathrm{~cm}$ long and $20 \mathrm{~cm}$ high in model scale. It effectively represents an infinitely long earth berm with a full-scale height of $5 \mathrm{~m}$.

\section{THEORY}

A previously published theory ${ }^{2}$ was used for comparison with the experimental data obtained. The theory is based upon uniform theory of diffraction ${ }^{3}$ (UTD) in combination with well-established formulas for sound propagation over finite impedance ground.

The UTD calculations are based upon the expressions originally given by Kouyoumjian and Pathak ${ }^{3}$ for diffraction by a wedge of infinite impedance. The diffracted velocity potential is [the sound rays being normal to the edge (see Fig. 2) using $e^{-i \omega t}$ notation]

$$
\begin{aligned}
\Phi= & \frac{e^{i k R_{1}}}{R_{1}}\left[V\left(r_{0} r_{1} / R_{1}, \theta_{1}-\theta_{0}\right)\right. \\
& \left.+V\left(r_{0} r_{1} / R_{1}, \theta_{1}+\theta_{0}\right)\right] .
\end{aligned}
$$

Using $A=r_{0} r_{1} / R_{1}$ one obtains

$$
\begin{aligned}
& V(A, \theta)=V^{+}(A, \theta)+V^{-}(A, \theta), \\
& V^{ \pm}(A, \theta)=\frac{-e^{i \pi / 4}}{\sqrt{2 \pi k A}} \frac{1}{2 \nu} \cot \left(\frac{\pi \pm \theta}{2 \nu}\right) F^{\prime}\left[X^{ \pm}(\theta)\right], \\
& X^{ \pm}(\theta)=2 k A \cos ^{2}\left[\left(2 N^{ \pm} \nu \pi-\theta\right) / 2\right], \\
& F^{\prime}(z)=-2 i \sqrt{z} e^{-i z} F(\sqrt{z}) .
\end{aligned}
$$

Here, $k$ is the wave number, $\nu=2-T / \pi, R_{1}=r_{0}+r_{1}$, and $F$ is the Fresnel integral. $N^{+}$and $N^{-}$are determined from

$$
N^{+}= \begin{cases}0, & \text { for } \theta \leqslant \pi-T \\ 1, & \text { for } \theta>\pi-T\end{cases}
$$

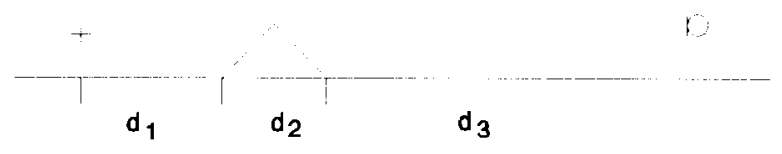

FIG. 1. Geometry of earth bern on ground. Source height $h_{\mathrm{r}}=1.25 \mathrm{~m}$, $d_{1}=12.5 \mathrm{~m}, d_{2}=10 \mathrm{~m}, d_{3}=30 \mathrm{~m}$, receiver height $h_{r}$, berm height $5 \mathrm{~m}$ in all cases. 


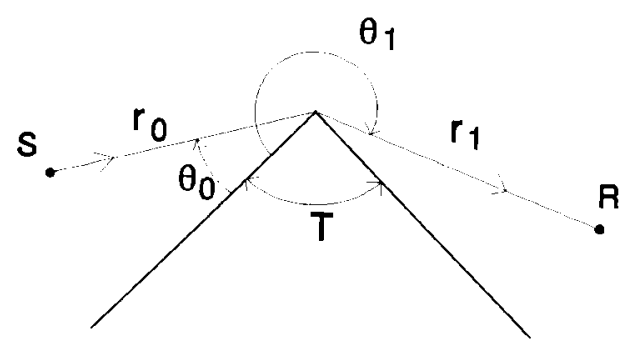

FIG. 2. Incident and diffracted ray for a wedge. $R_{1}+r_{0}+r_{1}$.

$$
N^{-}= \begin{cases}-1, & \text { for } \theta<T-\pi, \\ 0, & \text { for } T-\pi \leqslant \theta \leqslant 3 \pi-T, \\ 1, & \text { for } \theta>3 \pi-T\end{cases}
$$

The UTD formulation is believed to be of the same order of accuracy as, for instance, the formulas developed by Medwin, ${ }^{4,5}$ Hadden and Pierce, ${ }^{6}$ and Raspet et al. ${ }^{7}$ A recent investigation by Saunders and Ford ${ }^{8}$ using explosive sources concludes that the theories of Medwin and Hadden and Pierce are reasonably successful when compared with their experimental data.

The ground below the earth berm is taken into account by means of spherical wave reflection calculations as described in the original reference ${ }^{2}$ as well as in Saunders and Ford. ${ }^{8}$

The theory provides results in the frequency domain. In the following section calculated results in the time domain are shown. They are obtained by a convolution of the measured free-field impulse response of the spark source signal at the distance in question in the scale model with the theoretical impulse response of the surface. The convolution was realized as a multiplication in the frequency domain and the result was then transformed into the time domain by means of a fast Fourier transform.

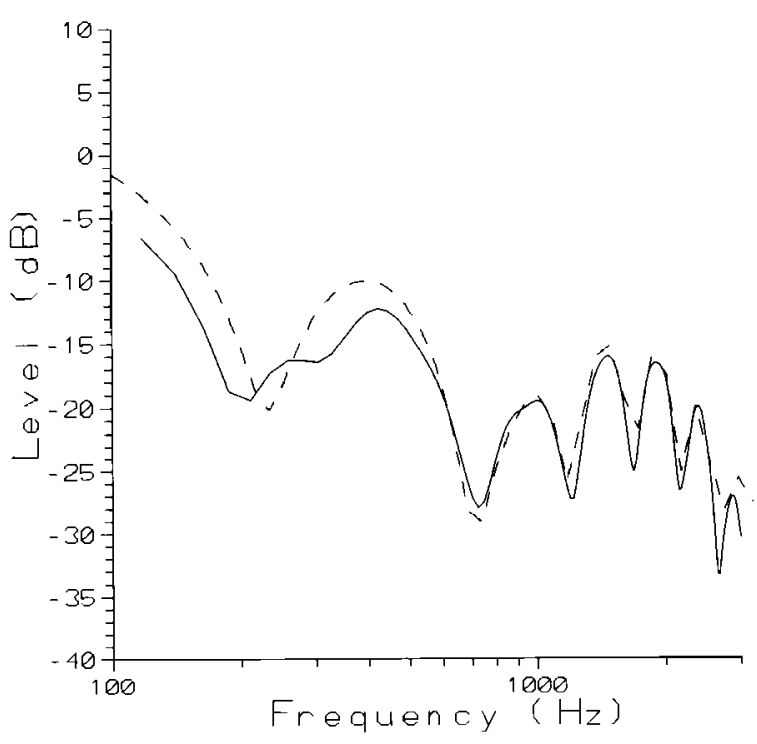

FIG. 3. Sound pressure level re: free field. Full curve: measured data, interrupted curve: calculated data. Receiver height $0.5 \mathrm{~m}$ (full scale).

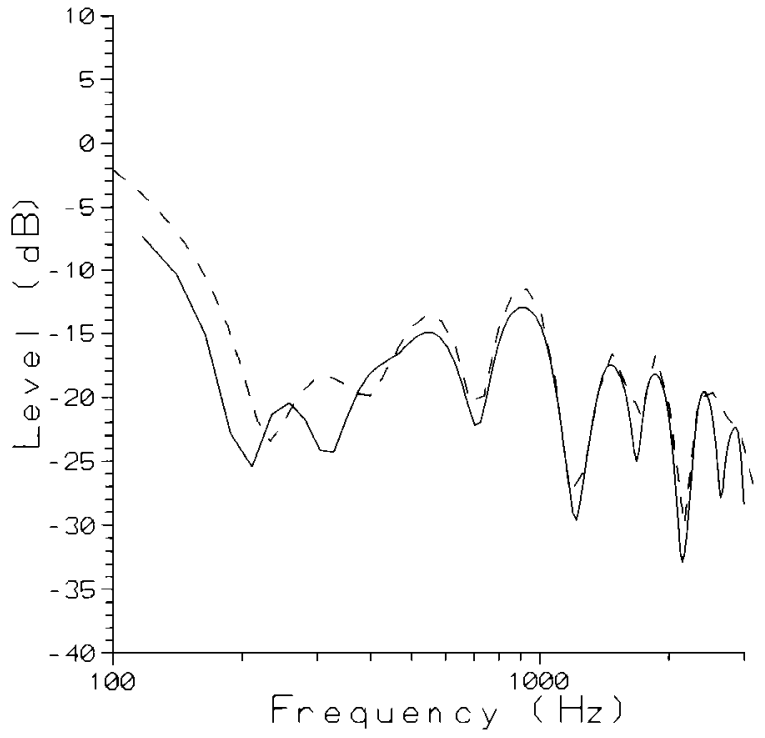

FIG. 4. Sound pressure level re: free field. Full curve: measured data, interrupted curve: calculated data. Receiver height $1.25 \mathrm{~m}$ (full scale).

\section{RESULTS}

In Figs. 3-6 measured and calculated sound pressure levels are shown for increasing receiver heights and as a function of the scaled frequency. The calculations were made for finite impedance ground $\left(500 \mathrm{kN} \mathrm{s} \mathrm{m}^{-4}\right.$ in the DelanyBazley model) and for hard wedge. The theory and experiments are seen to agree very well. The uniform diffraction theory involved is a high frequency approximation and some deviations must therefore be expected at low frequencies. In Figs. 5 and 6 additional measured results indicated by the + symbols have been included. These result from truncating the measured impulse responses before the arrival of the last ground reflection, i.e., the reflection from the ground below the receiver. The difference between the + symbols and the

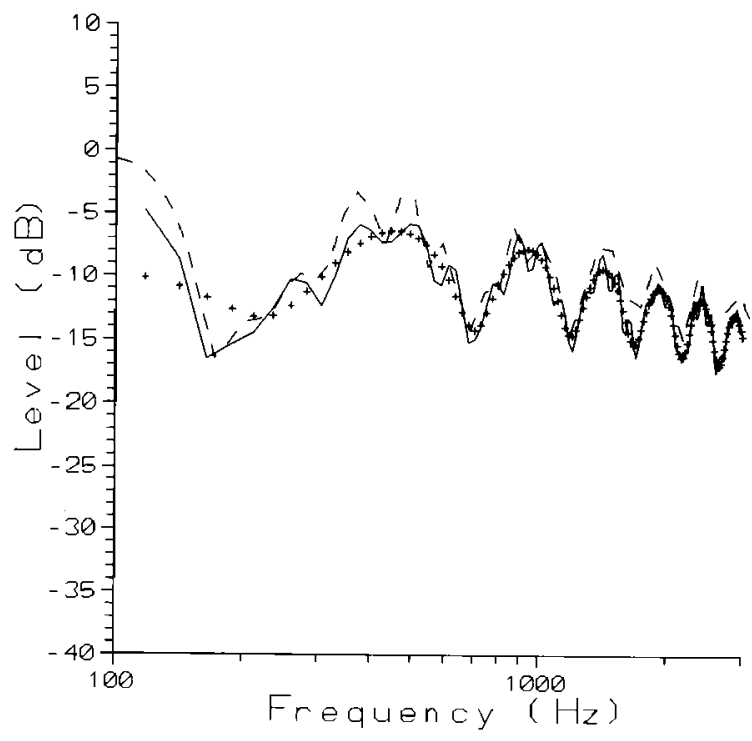

FIG. 5. Sound pressure level re: free field. Full curve: measured data, interrupted curve: calculated data. Receiver height $10 \mathrm{~m}$ (full scale). $(+)$ : Measured data obtained by discarding the ground under the receiver. 


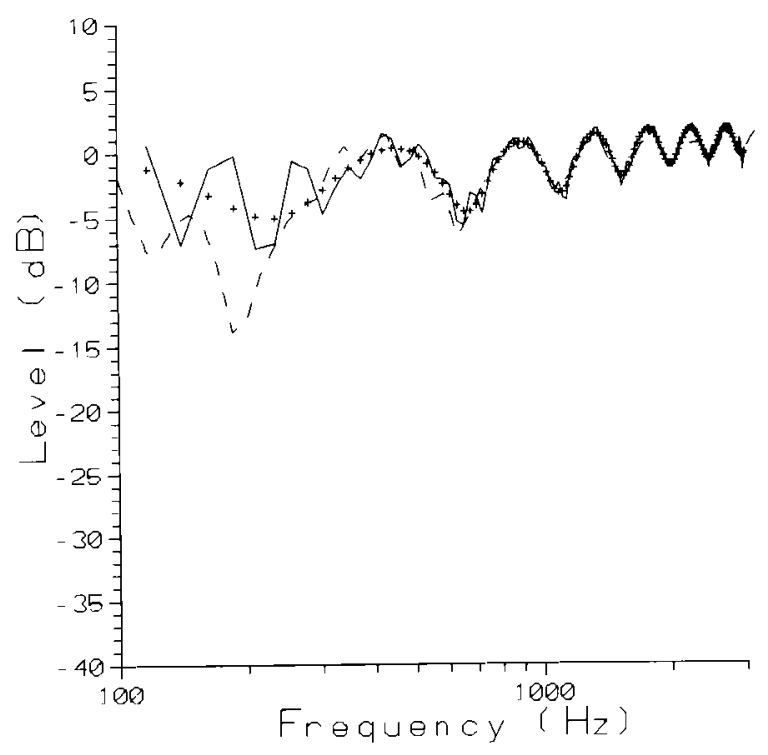

FIG. 6. Sound pressure level re: free field. Full curve: measured data, interrupted curve: calculated data. Receiver height $15 \mathrm{~m}$ (full scale). $(+)$ : Measured data obtained by discarding the ground under the receiver.

full curves reveal that the influence of the relatively distant ground below the receiver is the cause of the low frequency interference pattern.

In Figs. 7-9 time domain results are shown for the cases dealt with in Figs. 3 and 4 and for the reference signal corresponding to free-field propagation over the same distance as used in the measurements involving ground and earth berm. From the time domain results the specific arrival of the direct (diffracted) ray passing the vertex of the berm is seen followed by arrivals associated with ground reflected ray paths. Hence, the events identified with numbers in the figures are associated with source-vertex receiver (No. 1), source-vertex-mirror receiver (No. 2), mirror source-vertex receiver (No. 3), and mirror source-vertex-mirror receiver (No. 4). The agreement between measured and calculated

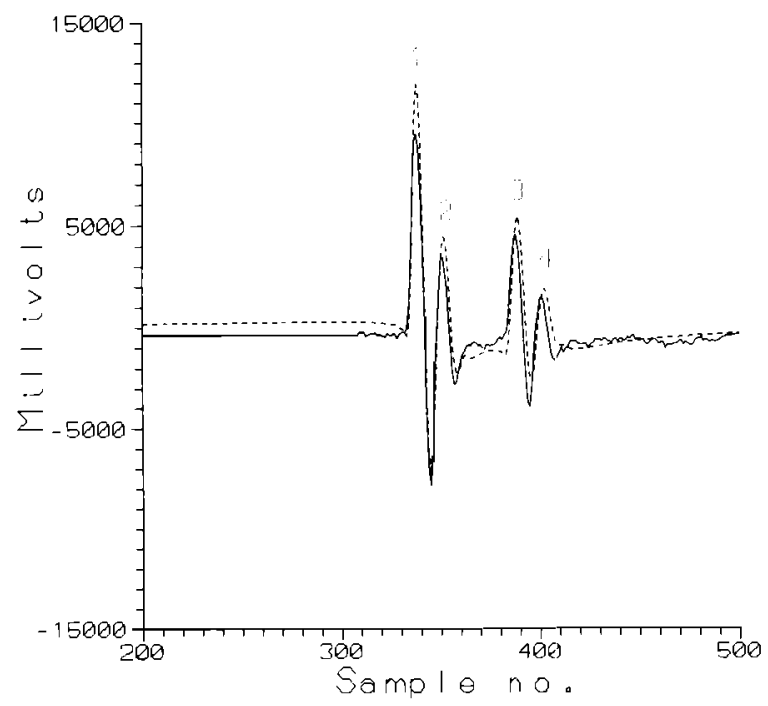

FIG. 7. Impulse response corresponding to Fig. 3. Full curve: measured data, interrupted curve: calculated data.

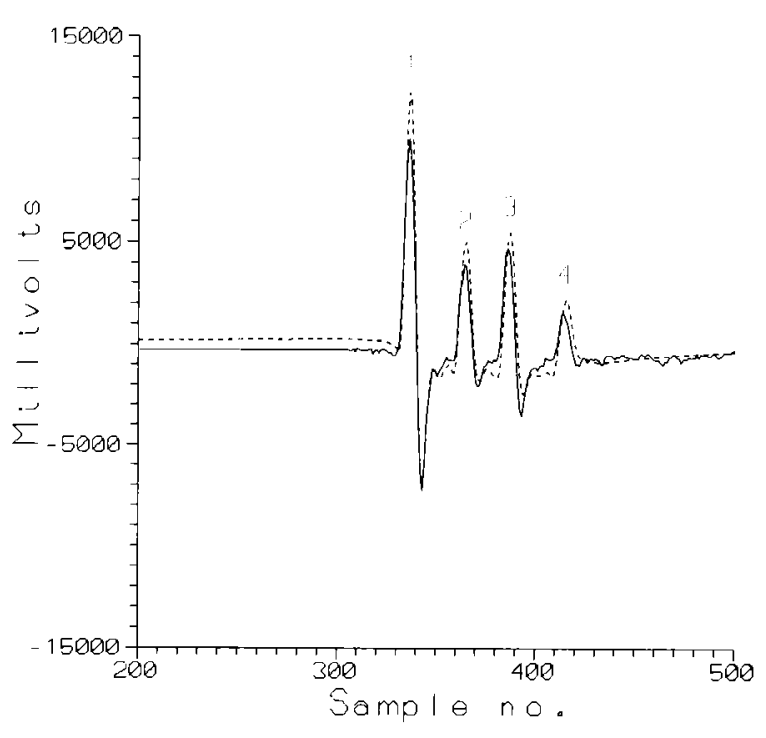

FIG. 8. Impulse response corresponding to Fig. 4. Full curve: measured data, interrupted curve: calculated data.

impulse responses is seen to be very good since all major features in the measured curves are reproduced in the calculated ones. The slight deviation between measured and calculated peak heights is believed to be caused by inaccuracies in the calculation model and possibly by a weak nonlinearity in the measurements.

\section{CONCLUSION}

Scale model experiments have confirmed the applicability of calculation models making use of uniform diffraction theory. The measured impulse responses have revealed the expected arrivals according to ray theory and the impulse responses have been reproduced by application of uniform diffraction theory.

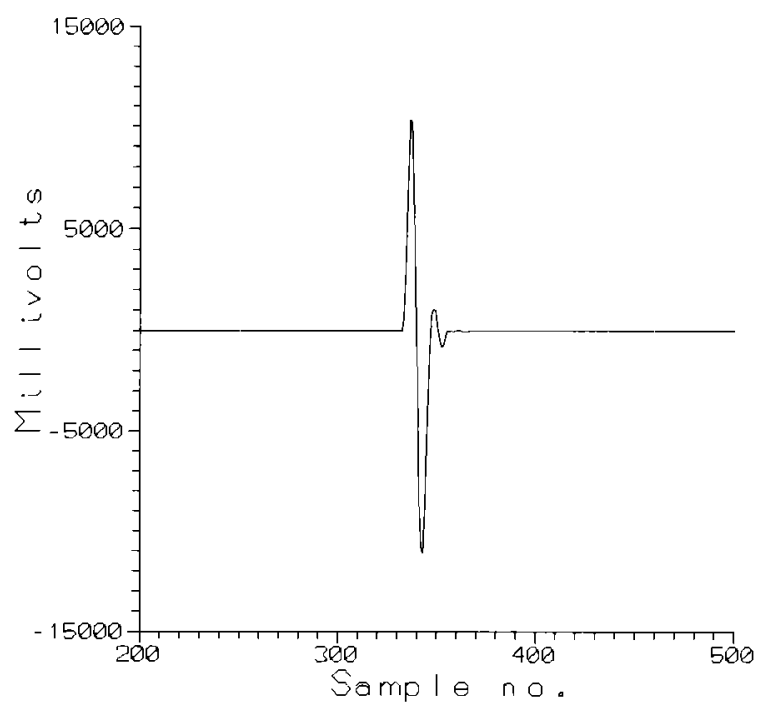

FIG. 9. Measured impulse response corresponding to free field. Impulse response is attenuated $20 \mathrm{~dB}$ relative to the data in Figs. 7 and 8 . 
'K. B. Rasmussen, "Scale-model simulation of sound propagation over an impedance discontinuity," INTER-NOISE 93 Proceedings, Leuven, Belgium, 1711-1714 (1993).

${ }^{2} \mathrm{~K}$. B. Rasmussen, "On the effect of terrain profile on sound propagation outdoors," J. Sound Vib. 98, 35-44 (1985).

${ }^{3}$ R. G. Kouyoumjian and P. H. Pathak, "A uniform geometrical theory of diffraction for an edge in a perfectly conducting surface," Proc. IEEE 62 1448-1461 (1974)

${ }^{4}$ H. Medwin, "Shadowing by finite noise barriers," J. Acoust. Soc. Am. 69, 1060-1064 (1981).

${ }^{5}$ H. Medwin, E. Childs, and G. M. Jebsen, "Impulse studies of double diffraction: A discrete Huygens interpretation," J. Acoust. Soc. Am. 72, 1005-1013 (1982)

${ }^{6}$ W. J. Hadden and A. D. Pierce, "Sound diffraction around screens and wedges for arbitrary source locations," J. Acoust. Soc. Am. 69, 12661276 (1981).

${ }^{7}$ R. Raspet, J. Ezell, and S. V. Coggeshall, "Diffraction of an explosive transient," J. Acoust. Soc. Am. 79, 1326-1334 (1986).

${ }^{8}$ D. J. Saunders and R. D. Ford, "A study of the reduction of explosive impulses by finite sized barriers," J. Acoust. Soc. Am. 94, 2859-2875 (1993). 